\title{
Residência Multiprofissional em Saúde da Família e Educação Permanente em Saúde: uma construção de vínculo entre a educação e o trabalho
}

The performance of the Multiprofessional Residency in Family Health in Permanent Education in

Health: a construction of the link between education and work

EI desempeño de la Residencia Multiprofesional en Salud de la Familia en Educación Permanente

en Salud: construyendo un vínculo entre educación y trabajo

\author{
Daniela de Freitas Rodrigues \\ ORCID: https://orcid.org/0000-0003-3392-3015 \\ Universidade Federal do Rio Grande, Brasil \\ E-mail:danifrer@hotmail.com \\ Cesar Francisco Silva da Costa \\ ORCID: https://orcid.org/0000-0001-6933-9705 \\ Universidade Federal do Rio Grande, Brasil \\ E-mail: hspcesar@furg.br \\ Priscila Munhoz Duarte \\ ORCID: https://orcid.org/0000-0003-4657-5662 \\ Universidade Federal do Rio Grande, Brasil \\ E-mail: priscilamunhozduarte@hotmail.com \\ Prisciane Cardoso Silva \\ ORCID: https://orcid.org/0000-0001-5327-1785 \\ Universidade Federal do Rio Grande, Brasil \\ E-mail: priscianecardososilva@gmail.com
}

\begin{abstract}
Resumo
Este artigo objetiva analisar de que forma a Residência Multiprofissional em Saúde da Família contribui para a Educação Permanente em Saúde da equipe da Estratégia Saúde da Família. Para isso, utilizamos como procedimentos metodológicos a pesquisa qualitativa, do tipo exploratória descritiva. $\mathrm{O}$ estudo ocorreu com trabalhadores da equipe multiprofissional de uma Unidade Básica Saúde da Família, localizada no município do Rio Grande/RS. A coleta de dados se desenvolveu por entrevista semiestruturada, gravada, com uso da técnica de grupo focal. O método utilizado para a análise qualitativa foi baseado na análise de conteúdo. Os resultados foram apresentados em três categorias temáticas: 1) Contribuições da Residência Multiprofissional em Saúde da Família através da Educação Permanente em Saúde 2) Mudanças no processo de trabalho da equipe 3) A importância e as formas de abordagem da Educação Permanente em Saúde. Evidencia-se que o residente multiprofissional é um catalisador de estímulos, pois agrega mudanças com vistas à formação e ao desenvolvimento pessoal, profissional e das equipes, por meio da ferramenta Educação Permanente em Saúde. Concluiu-se que quando a Residência Multiprofissional em Saúde da Família utiliza a educação como fundamento pedagógico, ela reorganiza o processo de trabalho, por meio da atualização de temas emergentes, estimula a reflexão e a discussão de casos com olhar multiprofissional e ainda institui o espaço de Educação Permanente em Saúde, que adiante qualificará a integralidade da atenção, o acolhimento, a clínica ampliada e a humanização do cuidado.
\end{abstract}

Palavras-chave: Educação permanente em saúde; Equipe multiprofissional; Equipe interdisciplinar; Estratégia saúde da família.

\begin{abstract}
This article aims to analyze how Multiprofessional Residency in Family Health contributes to the Permanent Health Education of the Family Health Strategy team. For this, we used qualitative research, descriptive exploratory type as methodological procedures. The study takes place with workers from the multidisciplinary team of the São João Family Health Basic Unit, located in the city of Rio Grande/RS. Data collection was performed by semi-structured interview, recorded, through the focus group technique and, for qualitative analysis, the method used was based on content analysis. The results were presented in three categories: 1) Contributions of Multiprofessional Residency in Family Health through Permanent Health Education 2) Changes in the work process of the team 3) The importance and ways of addressing Permanent Health Education. It is evident that the multiprofessional resident is an important catalyst of stimuli, because it adds changes with a view to training and personal, professional and team development, through the permanent health education tool. It was concluded that when the Multiprofessional Residency in Family Health uses education as a pedagogical foundation, it reorganizes the work process, through the updating of emerging
\end{abstract}


themes, stimulates the reflection and discussion of cases with a multidisciplinary view and also establishes the space of Permanent Education in Health, which will then qualify the integrality of care, the reception, the expanded clinic and the humanization of care.

Keywords: Permanent health education; Multiprofessional team; Interdisciplinary team; Family health strategy.

\section{Resumen}

Este artículo tiene como objetivo discutir cómo la Residencia Multiprofesional en Salud Familiar contribuye al equipo de Educación Permanente en Salud Familiar. Para ello, utilizamos la investigación cualitativa, el tipo exploratorio descriptivo como procedimientos metodológicos. El estudio se lleva a cabo con trabajadores del equipo multidisciplinar de la Unidad Básica de Salud Familiar, ubicada en la ciudad de Rio Grande/RS. La recopilación de datos se realizó mediante entrevista semiestructurada, grabada mediante la técnica del grupo focal y, para el análisis cualitativo, el método utilizado se basó en el análisis de contenido. Los resultados se presentaron en tres categorías: 1) Contribuciones de residencia multiprofesional en salud familiar a través de la educación continua de salud 2) Cambios en el proceso de trabajo del equipo 3) La importancia y formas de abordar la Educación Permanente para la Salud. Es evidente que el residente multiprofesional es un catalizador importante para los estímulos, ya que añade cambios con vistas a la formación y el desarrollo personal, profesional y de equipo, a través de la herramienta de educación para la salud en curso. Se concluyó que cuando la Residencia Multiprofesional en Salud Familiar utiliza la educación como base pedagógica, reorganiza el proceso de trabajo, a través de la actualización de temas emergentes, estimula la reflexión y discusión de casos con visión multidisciplinar y también establece el espacio de educación permanente en Salud, que luego evaluará la integralidad de la atención, recepción, ampliación de la clínica y humanización de la atención. Palabras clave: Educación Permanente en Salud, Equipo Multidisciplinario y Equipo Interdisciplinario.

Palabras clave: Educación permanente para la salud; Equipo multiprofesional; Equipo interdisciplinario; Estrategia de salud familiar.

\section{Introdução}

O trabalho na saúde apresenta especificidades, pois se trata de um labor reflexivo, em que a tomada de decisões implica a articulação de diferentes saberes que provêm de bases científicas, instrumentais e tecnológicas, e são sempre mediadas pela dimensão ético-política. Exige comprometimento e proatividade de profissionais que sejam capazes de articular experiências pessoais com conhecimentos e informações atualizadas, que possuam flexibilidade, disposição e criatividade necessárias para assumir mudanças e vencer os desafios que se colocam no cotidiano dos serviços. Como em outros campos de trabalho, a complexidade, a heterogeneidade e a fragmentação conceitual e técnica são características do processo de trabalho em saúde e desafiam cotidianamente os trabalhadores (Carvalho \&Teodoro, 2019).

Nessa esfera de conceitos e, diante da necessidade de aporte de tecnologias que visem dar suporte aos trabalhadores, $\mathrm{o}$ Sistema Único de Saúde (SUS) com suas bases estruturadas na reforma sanitária, tem como competência constitucional, através do artigo 200, inciso III, a atribuição de ordenar na formação e no desenvolvimento de recursos humanos na área da saúde (Brasil, 1988, Brasil, 2018). Para tanto, as políticas públicas, fundamentadas nas diretrizes do SUS, têm demonstrado importante papel para desencadear mudanças no processo de educação dos profissionais.

Nessa perspectiva, o Ministério da Saúde (MS), preconizou através da Portaria nº 198/GM (2004) a Política Nacional de Educação Permanente em Saúde (PNEPS), que se configura como aprendizado no trabalho, onde o aprender e o ensinar se incorporam ao cotidiano das organizações e ao trabalho. Nesse sentido, a Educação Permanente em Saúde (EPS), tem como eixo norteador a educação com potencialidades ligadas a mecanismos e temas que estimulem a reflexão sobre o processo de trabalho, autogestão, mudança institucional e transformação das práticas em serviço, por meio da proposta do aprender a aprender, de trabalhar em equipe, de construir cotidianos, como também colocar o sujeito no processo de autoconhecimento, de forma a se constituírem como objeto de aprendizagem individual, coletiva e institucional (Brasil, 2004, Brasil, 2018).

Nesse seguimento, com a operacionalização da PNEPS, torna-se imperativa a premissa de que as práticas dos profissionais de saúde respondam às demandas do Sistema Único de Saúde (SUS). Por isso, a EPS, é uma potente ferramenta de ação estratégica capaz de contribuir para a transformação dos processos formativos, das práticas pedagógicas, de atenção à saúde e para a organização dos serviços, empreendendo um trabalho articulado entre o sistema de saúde, em suas várias esferas 
da gestão, e as instituições formadoras (Neto \& Bandeira, 2019).

Ao encontro disso, foram criados programas através das Políticas de Saúde que objetivam formar e qualificar recursos humanos. Neste contexto, são incluídas as Residências Multiprofissionais em Saúde da Família, uma modalidade de pós graduação, latu sensu. Criadas através da cooperação entre o Ministério da Saúde e a Educação, visando inserir no SUS, profissionais qualificados, orientados pelos seus princípios e diretrizes (Brasil, 2021).

Desse modo, são norteadas por estratégias pedagógicas que se configuram através das Redes de Atenção à Saúde, tendo a atenção básica como espaço de trabalho. Utiliza-se também, de dispositivos de gestão ampliada o que garante a formação fundamentada na atenção integral, multidisciplinar e interdisciplinar e a educação permanente como eixo transversal e transformador da realidade (Brasil, 2021). O que se agrega a essa modalidade de formação resulta em ações educativas centradas nas necessidades de saúde da população, na equipe multiprofissional e na institucionalização da Reforma Sanitária brasileira, o que vem ao encontro do que preconiza a PNEPS e os princípios do SUS.

Sobre as ferramentas de apoio às equipes de Saúde da Família do município do Rio Grande - RS, destaca-se a Residência Multiprofissional em Saúde da Família (RMSF) que foi instituída em 2010, através da articulação entre a Universidade Federal do Rio Grande (FURG) e a Secretaria de Município da Saúde. A formação se dá através da inserção dos profissionais de enfermagem, educação física e psicologia nas Unidades Básicas de Saúde da Família (UBSF). Por isso, considerando os eixos que norteiam o fazer dos residentes no cotidiano laboral dos serviços, utilizou a EPS, tendo em vista a alta demanda de procura do usuário frente à UBSF, exigindo da equipe saber, constantemente, sobre os mais variados assuntos relacionados ao processo de saúde-adoecimento. Além disso, identificou-se a carência de espaços consistentes que visem fortalecer a interdisciplinaridade através da educação, de forma que os trabalhadores passem a sentir a necessidade do compartilhamento de conhecimento, bem como da discussão sobre metodologias organizacionais para o processo de trabalho.

Neste sentido, percebemos a necessidade de reconhecimento destes encontros de trocas e que os mesmos passem a ter significados, buscando com isso não só o aprimoramento do atendimento ao usuário, mas também à valorização de cada membro desta equipe no planejamento e no almejo de metas ao atendimento. Visamos, com isso, desmistificar as escalas hierárquicas culturalmente impostas relacionadas ao grau de importância de cada profissão e problematizar a busca por um atendimento cada vez mais multiprofissional e humanizado, enriquecido pelos próprios membros da equipe.

Diante de tal realidade e por saber que a RMSF, além de ser uma formação em trabalho, também conduz a ferramenta da educação como método de aperfeiçoamento do profissional da saúde e como forma de promover mudanças nas práticas de saúde do SUS. Acreditamos que a Educação Permanente em Saúde, especificamente, auxilia o profissional a produzir melhores resultados ao cidadão e as coletividades, além de trazer melhorias no processo de trabalho. Por isso, esse estudo buscou analisar de que forma a RMSF contribui para a Educação Permanente em Saúde da equipe da Estratégia Saúde da Família.

\section{Metodologia}

Trata-se de uma pesquisa qualitativa, descritiva e exploratória. Neste tipo de método o pesquisador realiza a interpretação das informações a partir da sua perspectiva do fenômeno em estudo, que pode ser feito através da coleta de dados por entrevistas com questões abertas (Pereira et. Al, 2018).

A coleta de dados ocorreu na cidade do Rio Grande - RS, nos meses de janeiro a abril de 2017, em uma UBSF, localizada na zona oeste do município. A população amostral foi escolhida de forma intencional, considerando que pertenciam ao ambiente laboral de formação dos residentes. Por esse motivo, corroboraram para o estudo, o total de 13 trabalhadores de composição da equipe multiprofissional, sendo 10 pertencentes à equipe mínima da ESF: um médico, um enfermeiro, um técnico de enfermagem, dois auxiliares de enfermagem e seis agentes comunitários de saúde; dois da equipe de saúde bucal: um odontólogo, um auxiliar de saúde bucal e, além dos profissionais técnicos, foi incluso um profissional de serviços gerais. 
Para construção do corpus da pesquisa, utilizou-se a técnica de grupo focal (GF) que se caracteriza por ser uma entrevista em grupo, na qual há um diálogo a respeito de um tema particular, vivenciado e compartilhado através de experiências comuns, ao receber estímulos apropriados para o debate (POPE \& MAYS, 2009). Os temas discutidos foram elaborados a partir de situações reconhecidas como relevantes acerca "de que forma a RMSF contribui para a Educação Permanente em Saúde da Estratégia Saúde da Família". A técnica de coleta foi escolhida por se tratar de uma equipe em que a realidade é o trabalho multiprofissional e interdisciplinar e, por isso, a aplicabilidade do GF trouxe resultados positivos para essa pesquisa.

Para esta etapa, cabe a contextualização, que inexistia a prática de educação Permanente em Saúde (EPS) no cronograma de atividades deste serviço. Por esse motivo, em maio de 2016, a equipe de residentes definiu aos trabalhadores os dias de ocorrência dessas atividades, que se estabeleceu na última quarta-feira de cada mês. Além disso, deliberou-se como premissa para essa organização: a participação de todos os profissionais nos encontros, o dever da prática atender a abordagem multiprofissional e interdisciplinar e os temas em discussão serem de escolha dos trabalhadores, tendo como referência a realidade laboral do território de responsabilidade sanitária da equipe. Para essa última premissa, enfatizou-se a necessidade de discussão em equipe para definição dos temas, considerando que deveria ser de relevância e aplicabilidade no fazer de todos núcleos profissionais envolvidos.

Essas datas, ocorreram na reunião semanal, quando a unidade de saúde atende somente casos urgentes, ficando dessa forma indisponível para as demais necessidades de rotina do serviço. Essa reunião é o momento que a equipe multiprofissional utiliza para discussão de casos de usuários e para organização dos processos de trabalho. Porém, a realidade desses encontros, convertia-se para organização de trabalhos burocráticos reprimidos pela demanda existente no serviço.

Após, de janeiro a abril de 2017, foi iniciado as práticas de grupo focal, quando foi possível discutir junto aos trabalhadores os objetivos desse estudo e a inclusão da coleta de dados no cronograma de EPS. Neste panorama, a técnica de grupo focal aconteceu na última quarta-feira de cada mês e contemplou a periodicidade de quatro sessões e, em cada uma dessas, houve um tema que norteou a discussão entre os participantes. Enfatiza-se que para cada encontro de GF, utilizou um roteiro semiestruturado construído com base nos objetivos dessa pesquisa, composto pelas seguintes questões: 1) Vocês percebem alguma mudança no processo de trabalho da equipe a partir da Educação Permanente em Saúde? Quais? 2) Quais os benefícios da Educação Permanente em Saúde no processo de trabalho da equipe? 3) Vocês consideram adequada a periodicidade e os temas abordados nas atividades de Educação Permanente em Saúde? Os encontros foram mediados pelo próprio pesquisador, que assumiu a função de moderador e o agente administrativo da unidade de saúde, que não arranja os sujeitos entrevistados, o qual executou a função de observador externo.

Salienta-se, ainda que no primeiro GF, o pesquisador explicou os objetivos da pesquisa e esclareceu questionamentos relativos às questões éticas, para posterior concordância dos participantes através da assinatura do Termo de Consentimento Livre e Esclarecido. Não ocorreram exclusões, uma vez que todos os sujeitos aderiram ao estudo.

Os encontros ocorreram no salão de reuniões de equipe, por tratar-se de um ambiente acolhedor, confortável e que assegura a privacidade dos entrevistados. Além disso, por ser um dia em que a unidade não está aberta para atendimentos externos e, por isso, livre de ruídos ou intervenções por parte das demandas dos usuários e do próprio processo de trabalho, o dia da semana e o ambiente facilitaram o debate, o que permitiu o aprofundamento nas discussões entre os participantes. Ainda, as sessões foram gravadas através de dois dispositivos de MP4 o que permitiu a transcrição e análise da entrevista.

A coleta de dados ocorreu a partir da aprovação do Comitê de Ética em Pesquisa da Universidade Federal do Rio Grande (CEP/FURG) e do Núcleo de Municipal de Educação e Saúde Coletiva (NUMESC) da Prefeitura Municipal do Rio Grande/RS. 
Os dados foram tratados através da Análise de Conteúdo, definida como um conjunto de técnicas de análise das comunicações, visando obter por procedimentos, sistemáticos e objetivos de descrição do conteúdo das mensagens, indicadores, quantitativos ou não, que permitam a inferência de conhecimentos relativos às condições de produção destas mensagens. Logo, este tipo de análise, utiliza-se da comunicação como ponto de partida, ou seja, é sempre feita a partir da mensagem e tem por finalidade a produção de inferências, que servem para esclarecer as causas da mensagem ou as consequências que elas podem causar (Bardin, 2011).

Para isso, o pesquisador atendeu as três etapas da análise, seguindo o passo cronológico indicado pelo autor, Bardin (2011): iniciando-se pela pré-análise, após pela exploração do material e, por fim, pelo tratamento dos resultados, da inferência e das interpretações. A primeira fase, considerada a fase de organização, se subdividiu em leitura flutuante e preparação do material, quando organizou-se os dados, de forma a sistematizar as ideias iniciais e de maior importância de cada diálogo.

Após, a classificação dos diálogos através da transcrição das falas, ocorreu o agrupamento por semelhança das ideias, a fim de que pudessem ser agrupadas e, posteriormente, exploradas e, por fim, interpretadas. Essa análise permitiu a visualização das seguintes categorias: 1) Contribuições da Residência Multiprofissional em Saúde da Família através da Educação Permanente em Saúde 2) Mudanças no processo de trabalho da equipe 3) A importância e as formas de abordagem da Educação Permanente em Saúde.

\section{Resultados}

Após aplicação da metodologia proposta, análise de conteúdo (BARDIN, 2011) foi possível identificar três categorias: 1) Contribuições da Residência Multiprofissional em Saúde da Família através da Educação Permanente em Saúde 2) Mudanças no processo de trabalho da equipe 3) A importância e as formas de abordagem da Educação Permanente em Saúde.

\subsection{As contribuições da Residência Multiprofissional em Saúde da Família através da Educação Permanente em Saúde}

Conforme a fala dos participantes foi possível perceber que as atividades da residência multiprofissional resgataram algumas práticas de educação e serviu para atualização, contribuindo de forma positiva, conforme relato:

[...] acho que a residência quando chegou ela veio resgatar algumas práticas que a gente, consumida pelo tempo e pela população muito grande, pelo excesso de trabalho, sobrecarga de trabalho a gente não estava conseguindo fazer. O espaço da quarta-feira ele era destinado mais a botar o serviço (burocrático) em dia, do que realizar qualquer tipo de capacitação, de atualização em algum assunto e com a chegada da residência isso veio a contribuir de forma muito positiva. (Antúrio)

Além disso, foi encontrado na fala dos participantes que a contribuição da residência através da EPS, ocorreu por meio da motivação dos trabalhadores, a partir da valorização do espaço de educação, trazendo com isso novas esperanças e diferentes formas de abordagem com a comunidade. Destacam que a RMSF estimulou a reflexão da importância de ocorrer as atividades educativas, justificado com a necessidade de parar e repensar o seu fazer, através do detalhamento de temas pertinentes ao cuidado do usuário, conforme relato:

[...] bom eu acho que vocês entraram na nossa equipe, nos trazendo pilha nova, gás. A gente já estava meio cansada, meio estressada, meio desiludida e vocês chegaram trazendo esperanças, maneiras, colocações diferentes que a gente poderia abordar a nossa comunidade, através da educação permanente. Foi maravilhoso. (Gloriosa 3)

[...] acho que contribuiu bastante, nos ajudou a parar um pouco e ver o tema mais detalhado, porque as vezes a gente sabe sobre aquela doença, geral e isso faz a gente lembrar de algumas coisas de que já estavam esquecidas, do tema. (Gardênia) 
Foi encontrado nos relatos que o processo de trabalho é mecanizado, em função da rotina, que mesmo sabendo sobre determinados temas, muitas vezes, os trabalhadores não os percebem nas suas práticas. Por isso, a residência multiprofissional contribui, através da EPS, na autoavaliação quanto ao entendimento e aplicabilidade de temas discutidos nos encontros de EPS. Percebe-se quando os profissionais relatam que a abordagem de alguns temas permitiu a eles visualizarem que há um empirismo no seu fazer, que realizam diversas práticas de forma rotineira ou por instinto. Diante disso, identificam que muitas vezes o trabalho realizado está correto e outras vezes não, o que permite ao profissional corrigir, conforme relato:

[...] quando alguém expõe algum assunto a gente fica pensando: "mas isso eu faço", mas a gente faz de maneira as vezes meia empírica ou faz por instinto ou faz pela rotina e quando a gente vê alguém expondo aquilo a gente vê que a gente está fazendo o trabalho certo muitas vezes, ou se está fazendo errado dá pra corrigir [...]. (Antúrio)

Relatam ainda, que ter o residente responsável pela Educação Permanente em Saúde é um ganho para a equipe da estratégia, pois esses profissionais são capacitados e possuem o conhecimento para ministrar as atividades de educação. Elucidam que a intervenção feita pela residência multiprofissional é resolutiva, de modo a dar respostas aos problemas encontrados no dia a dia, pois trabalham junto com a equipe dando subsídios de melhora para o atendimento ao usuário.

[...] qualquer conhecimento é bem-vindo [...] o residente é capacitado, vocês estão com o conhecimento fresquinho [...] o residente, realmente ele tem gás, tem vontade e tem o conhecimento [...] então é a melhor fonte, é uma fonte segura, em um momento que a gente pode e tem que parar na quarta-feira pra estudar, tendo brecha na agenda [...]. (Cravo)

[...] alguém dentro da nossa equipe que chegou pra nos ajudar, nos auxiliar e nos dar respostas, coisas que as gurias poderiam fazer, mas elas têm tanta coisa, que elas não conseguem, então pessoas a mais pra nos ajudar a resolver os nossos problemas [...]. (Gloriosa 3)

[...] por que a importância disso ter vindo com a residência multiprofissional, porque é uma das atividades me acredito da residência, de trabalhar junto com a equipe de dar subsídio de melhoria do atendimento pra essa equipe [...]. Sem dúvida a residência enriquece em todos os sentidos e muito na questão educação permanente [...]. (Astromélia)

\subsection{Mudanças no processo de trabalho da equipe multiprofissional}

Essa categoria visa identificar as mudanças que ocorreram com a inserção do espaço de Educação Permanente em Saúde na prática dos profissionais desta equipe. Conforme discussão entre os participantes foi possível identificar que os profissionais se sentem mais atualizados, a partir dos encontros de EPS, pois adquirem mais conhecimentos e inovações sobre os assuntos. Destacam que a atualização se deu de duas formas: de resgate de temas e de suas especificidades que já eram conhecidos pelos profissionais, mas que não eram lembrados e de inovação através da apresentação de assuntos que não eram conhecidos pela equipe, conforme relatos:

[...] mais conhecimento, a partir do momento que vocês nos capacitam pra isso, nós temos mais conhecimentos e inovações, porque a medida do tempo muitas coisas trocam, a gente está sempre por dentro dos assuntos, porque vocês estão nos ajudando através da educação permanente. (Gloriosa 2) 
[...] atualização, porque são várias coisas que modificaram (ao longo dos anos, do processo saúdeldoença) e a gente não acompanhou [...]. E quando vocês fizeram a educação permanente, seja sobre as vacinas, seja sobre a tuberculose [...] umas coisas foram de resgate, que eram coisas que a gente não lembrava mais e outras coisas novas realmente, de mudanças que vinham acontecendo e que a gente não tinha se atualizado. Então foi isso, foi um resgate e uma atualização de muita importância. (Astromélia)

[...] a residência trabalhar com educação permanente é útil para a unidade, para os trabalhadores, porque sempre traz coisas novas [...]. (Margarida) [...] atualização. (Gloriosa 4)

Outra mudança relevante percebida na fala dos participantes foi que as atividades de EPS com a residência permite que ocorra troca de conhecimento entre os profissionais, pois um contribui com o outro, há troca de experiências e de ideias. E que os temas abordados trouxeram benefícios para o profissional trabalhar melhor, pois desmistificaram alguns conceitos que eram permeados pelo preconceito.

[...] a gente acaba um contribuindo com o outro, mas é um momento que a gente pode trocar ideias, trocar experiências e também educação. [...] no assunto tuberculose, por exemplo, em primeira instância a gente fica com aquele preconceito: quero distância. Depois da educação permanente já não. Várias pessoas passaram por aqui que a gente sabia que tinha, então naturalmente, sendo que tu tens que ter cuidado, tem que ter prevenção, mas não também ficar aquele receio demais, aquela coisa assim. Falar sobre o tema trouxe bastante benefícios para eu poder trabalhar [...]. (Margarida)

[...] era um contribuindo com o outro, o que um não sabia o outro vinha e falava sobre o tema, esclarecia e vocês também junto [...] foi algo assim muito, muito bom. (Astromélia)

Segundo os participantes, a Educação Permanente em Saúde passou a ser um espaço de esclarecimento de assuntos que qualificam a informação prestada ao paciente e que isso modifica o processo de trabalho, pois ocorre um retorno positivo por parte do usuário também, conforme relato:

[...] eu acho que a gente fica mais esclarecida, como eu te disse, tu lembras daquilo, como é [...] e tu consegue passar para o paciente. (Gardênia)

\section{[...] vejo nas escolas as crianças que vão melhorando. (Copo de leite)}

Relatam ainda que a maneira como foram pensados os encontros pelas residentes serviu para refletir a importância da Educação Permanente em Saúde e da necessidade da equipe se apropriar dessa prática, se organizando e parando para fazer mais. Acrescentam também que os encontros de educação modificam o seu dia a dia, pois estimulam a mudança de comportamento e de pensamento, a partir das perguntas feitas de angústias, de medo de contágio, de esclarecimento do que é a patologia e dos cuidados na visita domiciliar. Conforme relatos:

[...] acho que serviu assim, pra gente refletir a importância e que a gente tem também que se organizar e parar para fazer mais [...]. (Copo de leite) 
[...] Completamente, porque teve várias perguntas que foram feitas aqui, que as gurias fizeram de angústias [...] vou dar o exemplo da Tuberculose, de angústias de medo de contágio, aquela coisa na visita domiciliar e aí com o esclarecimento realmente do que é, de como é que iria se contaminar e toda essa situação [...] eu tenho certeza que houve uma mudança de comportamento, houve uma mudança de pensamento em relação àquela patologia (tuberculose) [...]. (Astromélia)

\subsection{A importância e as formas de abordagem da educação permanente em saúde}

Esta categoria apresenta, segundo os participantes, a importância de implantar, avaliar e estabelecer os principais temas para EPS, bem como a periodicidade e as dinâmicas dos encontros.

Quanto à periodicidade dos encontros, uns acreditam que uma vez ao mês é o ideal, pois não há brecha na agenda para mais encontros e que seria cansativo. Enquanto que outros justificam a necessidade de maior frequência no mês, porque quanto mais encontros, melhor. Estas manifestações podem ser identificadas conforme os relatos:

\section{[...] uma vez ao mês foi ótimo, acho que mais seria difícil. (Copo de leite)}

\section{[...] foi a ideal. (Gloriosa 5)}

[...] não seria ruim mais vezes no mês, mas pra quem não tem nada, uma vez no mês já é bom. (Gardênia)

[...] poderia ser mais frequente (mais de uma vez no mês), porque as pessoas ficam mais esclarecidas, porque quanto mais melhor. (Margarida)

[...] não tem brecha pra isso, não tem condições pra isso. Uma quarta foi muito bom, porque ao mesmo tempo, era rápido, quando a gente viu já tinha passado. (Astromélia)

A organização do cronograma mensal de Educação Permanente em Saúde, proposto pela residência, foi um benefício, tendo em vista que os profissionais demonstraram não ter um espaço de escuta, de qualificação e de explanação de dúvidas, em função da demanda diária. Ter data prévia permitiu ao profissional se programar e, assim, elencar suas dúvidas, para posteriormente serem esclarecidas nos encontros de EPS.

[...] foi um momento bem válido, porque no dia a dia tu tens muitas dúvidas e se tu tens em vista que naquele dia tu vai ter alguém para esclarecer as tuas dúvidas tu acabas focando e naquele dia tu pergunta, porque senão a demanda te atropela e tu acaba assim [...] depois eu vou ver e o depois não chega nunca. Que nem agora está de novo, a gente não tem (EPS), a gente tem pra quem perguntar, mas a gente não tem aquele momento exato (os encontros de EPS). Quando saio de casa penso que vou perguntar, mas tu chegas aqui, a gente já esqueceu, então é muito válido, é muito importante [...]. (Gloriosa 5)

Contrapondo ao cronograma da residência, ficou evidente como sendo uma dificuldade para a realização de EPS, não existir no cronograma da ESF uma data específica para efetivar este trabalho na UBSF. Além disso, frisam que o tempo para planejar os encontros é escasso, em função da alta demanda de atendimentos e de serviços burocráticos e que por esses entraves a EPS passou a ser uma conversa de corredor. Soma-se a isso o fato de que o residente é o mais apto a assumir esta 
atividade, pois possuem dentro das atividades da residência, tempo pra isso, diferente da equipe da estratégia onde foi realizado este estudo.

[...] olha nós temos que fazer produtividade, nós temos que digitar, fazer receita, olhar exame, então na quarta-feira virou o dia da gente praticamente realizar os atrasos de tarefas que tu não podes fazer na semana. É [...] eu não diria impossível, mas é praticamente impossível abordar algum assunto (EPS). A educação permanente vira uma conversa de corredor, discutindo casos [...] porque não tem tempo. (Antúrio)

[...] a educação permanente não existia na unidade antes da residência, não tinha pelo tempo [...] acho que o principal motivo que dificulta a realização de educação permanente é o tempo, pois falta semana na semana [...] e falta dentro do cronograma da estratégia um espaço para educação permanente na unidade [...]. (Gardênia)

\section{[...] o que dificulta é a burocratização e a alta demanda. (Gloriosa 1)}

[...] Falta de tempo (Gloriosa 2 e 3)

[...] não temos tempo para educação permanente, temos tempo para o pessoal lá de fora (demanda)

[...]. (Margarida) [...] um exemplo, terça tem reunião de coordenadores, eu tenho que passar esta reunião na quarta para a equipe [...] então assim é muito difícil a gente ter o foco e usar a quarta-feira para a educação permanente [...] pra fazer uma educação permanente não é decidir eu vou fazer, tu tem que ler, tu tem que te organizar pra fazer isso e aqui dentro não tem momento pra te preparar [...] então os residentes tem tempo pra isso [...] e nós não conseguimos realmente [...]. (Astromélia)

[...] é importante a gente receber a educação permanente, mas também passar o que a gente sabe e isso acaba não acontecendo pela falta de tempo e de repente pela organização. (Copo de leite)

[...] realmente a gente não tem tempo, a gente está numa reunião fazendo chumaço, a gente está te ouvindo e cortando gaze [...] a gente realmente não se atualiza, a prefeitura não nos dá oportunidade de se atualizar, ou estudo em casa pra atualizar alguma técnica ou aqui (na UBSF) não dá [...]. (Cravo)

Outro ponto que está relacionado ao cronograma mensal da ESF é o desmembramento da equipe para capacitações fora da unidade, em praticamente, todas as 33 quartas-feiras e, que tal fato dificulta a efetivação da EPS na unidade. Destacam com isso que ter EPS não depende somente da organização da equipe, mas da ajuda da Coordenação da Estratégia Saúde da Família. A seguir são apresentados os depoimentos que exemplificam esse tipo de situação.

[...] o dia que seria para educação permanente na quarta-feira, a própria coordenação já estipula pra nós o que fazer ou senão nos separa. Enfermeira está em determinado lugar sendo capacitada, médica está em determinado lugar, e separa para capacitações e desmembra a equipe. Então tem que ser um momento em que estivéssemos todas aqui dentro e esse momento a gente só tem tempo na quarta-feira. [...]. (Astromélia) 
[...] se depender só de nós não sai, porque vamos pensar em colocar na primeira quarta do mês e a enfermeira tem capacitação, na outra tem pra outro profissional, então assim, eu acho que tem que ter um tempo destinado para isso [...] o que emperra é o tempo de todo mundo junto para educação permanente na unidade, porque organizar, a gente se organiza. (Gardênia)

\section{[...] nunca tem todos na quarta, o que fica muito difícil. (Gloriosa 1)}

Quanto à forma de conduzir os encontros pela RMSF, segundo os participantes, a dinâmica era muito boa, não era cansativa, todos participavam e, por isso, não percebiam o tempo passar. Ter uma dinâmica para os encontros de EPS, na visão dos participantes, facilita a implementação das práticas de EPS, pois tal método faz toda a diferença. Acrescem ainda que o estímulo através de perguntas, discussões, adivinhações e brincadeiras tornaram os encontros "leves" e prazerosos. Conforme relatos:

[...] a dinâmica também que vocês utilizavam, como montavam para apresentar era muito boa, não era cansativo, não era aquela coisa, lendo, lendo [...], passava muito rápido, nem percebíamos o tempo passar. (Gloriosa 4)

[...] o trabalho era de participação de todas, um espetáculo [...] até em termos de equipe, a gente sentou e discutiu o tema, mas era uma coisa leve, uma coisa prazerosa, que entrava brincadeira junto, entrava o questionamento, era um aprender prazeroso, era um aprender em equipe [...]. (Astromélia)

[...] era participação através de perguntas, adivinhações, passava muito bem [...] era uma coisa lúdica [...] a educação permanente tem valor dependendo de quem a administra. (Antúrio)

[...] eu gostei da forma que a residência abordou, porque não sei se vocês trazem umas ideias mais assim [...] legais, divertidas, que interage e, não assim "eu vou te dar um folder, eu vou ler e vocês acompanhem”, eu acho que tu aprendes mais com dinâmicas, com jeito divertido de fazer a educação permanente; faz toda a diferença, fica bem mais interessante [...]. (Gardênia)

[...] vocês trabalhavam de uma maneira maravilhosa, nos colocando, nos fazendo falar, nos fazendo interagir com vocês. Isso foi maravilhoso [...] não foi chato e massacrante. (Gloriosa 3)

Ficou claro na fala dos participantes que a escolha dos temas para EPS, também é um método facilitador para despertar interesse dos trabalhadores pelas atividades de EPS. Segundo eles, a escolha dos temas não se dá através de um assunto geral apresentado para todas as Unidades de Estratégias de Saúde da Família, mas sim a partir de uma discussão entre cada equipe para então direcionar o enunciado para a sua realidade. Segundo relatos é importante consultar os profissionais, saber quais são as dúvidas, quais temas são relevantes ao cotidiano da equipe, pois a EPS deve ser focada no dia a dia, na realidade local.

[...] na educação permanente da residência, não vinha qualquer assunto e vamos fazer educação sobre isso, não, eram assuntos que estavam dentro da nossa realidade, que trazem mais angústias, o que traz mais dúvidas, o que a gente realmente trabalha no nosso dia a dia, que tem necessidades pra resolver a nossa demanda [...] agora mesmo 
vamos ter a capacitação da secretaria sobre esporo tricose, nunca vi nesta unidade em 14 anos, então é coisa que foge do dia a dia, a educação permanente tem que ter foco no teu dia a dia, no que tu está precisando, não chegar e porque é o mês de determinada doença ou o Governo Federal mandou discutir aquele tema no mês, não! Tem que trabalhar coisas da realidade [...]. (Astromélia)

[...] Aqui não! Aqui elas (residentes) vão falar o que a gente quer saber, porque antes a gente foi consultada, para saber o que a gente queria, quais eram as dúvidas [...]. (Gloriosa 5)

[...] porque é muito fácil nos chamarem lá e dizer a mesma coisa para todo mundo, mas cada um tem a sua realidade, dentro do que eles querem passar [...] eu sempre achei que a educação permanente tem que ser dentro da unidade, eu acho que é mais proveitoso [...] nós vamos mostrando a nossa realidade, não é algo geral, cada um tem a sua. (Gloriosa 6)

[...] eи acho importante questionar também, todo mundo dar uma opinião, do que gostaria, no que tem mais dúvidas, como vocês (residência) fizeram [...] não adianta ser para todo mundo (todas as equipes da ESF), deve ser focado naquela área que tem problema [...] temas como vocês fizeram, coisas que também fazem parte do nosso cotidiano. (Copo de leite)

[...] eu acho que esses temas mudam de área por área [...] é importante conversar com a equipe pra ver isso. (Gardênia)

Outra facilidade encontrada é a escolha da temática dos encontros ser focada no encontro multiprofissional, pois segundo os participantes, esse método de abordagem é fabuloso. Segundo eles o grande diferencial é que são temas que interessam todas as categorias profissionais, sendo considerado um fator positivo, pois são pessoas que trabalham com o mesmo público e a mesma demanda. Isso pode ser identificado nos relatos abaixo:

[...] acho muito importante também que foram temas que envolviam todos os profissionais. Não adianta tu fazer uma educação permanente que envolva só agente comunitário, que a equipe técnica vai ficar parada. Não adianta que envolva só a equipe da odontologia que os outros vão ficar parados [...] então acho que a escolha dos temas foi fabulosa, por exemplo, calendário vacinal, desde o agente, médico, enfermeiro [...] todos precisam. Tuberculose, nós precisamos no posto, os agentes comunitários precisam porque entram nos domicílios [...] então são temas que interessam a todas as categorias profissionais, eu acho que isso foi fabuloso. (Antúrio)

[...] achei muito bom um mesmo tema para toda equipe e no mesmo dia, porque todas trabalhamos com o mesmo público, a mesma demanda, então eu acho que a educação permanente pode ser sempre assim [...]. (Gloriosa 3)

\section{Discussão}

Diante da análise dos dados apresentados percebeu-se uma inquietação referente à necessidade de valorização do cotidiano dos trabalhadores, no que tange ao aspecto Educação Permanente em Saúde, pois há uma mobilização de falas que discutem sobre a necessidade do embasamento das temáticas para essa prática ser focado no dia a dia dos trabalhadores. Acredita-se que envolver os profissionais que estão inseridos na realidade do local na qual ocorre as atividades fornece mais 
coerência às temáticas abordadas, pois eles são capazes de descrever e priorizar os principais problemas de saúde da população que atendem.

Percebemos, com isso, que há uma necessidade da Gestão da Estratégia de Saúde da Família fazer uma análise situacional de cada área de cobertura, dando ênfase aos fatores que circundam e estão inerentes ao local que será direcionado a Educação Permanente em Saúde, através da participação dos trabalhadores. Entendemos que tais mudanças são necessárias para a qualificação das práticas de formação, pois quando a gestão modifica o modelo tradicional verticalizado, caracterizado pela priorização da individualidade e fragmentação da equipe, há espaço para a horizontalização da organização do trabalho, onde as decisões que eram escaladas pela gestão da ESF passam a ser tomadas por meio da atuação do coletivo.

Este entendimento baseia-se ao levar em consideração de que segundo Sena et al. (2017) a efetivação de práticas de Educação Permanente em Saúde fragmentadas, verticalizadas, pontuais e individualizadas é ineficaz e de baixa potencialidade para modificar o cotidiano dos trabalhadores. Nesse entendimento, Campos, Sena, \& Silva (2017) e Ferreira et al. (2019), sobrelevam que as intervenções educacionais devem atender as particularidades dos serviços e, por essa razão, a interação entre gestores e profissionais da saúde é fundamental. Isso significa, segundo o autor, que os mesmos devem "mergulhar" no cotidiano e na complexidade dos problemas sanitários existentes, utilizando-se de uma leitura teórica e crítica, para transformarem os objetivos das ações educacionais, tornando-as profícuas e que possam, efetivamente, impactar na ressignificação e reestruturação dos processos de trabalho.

No contexto da sensibilidade do olhar do gestor sobre a equipe multiprofissional atuante na ESF, cabe sustentar através da constatação de Rodrigues et al. (2020), que o seguimento de educação permanente abarca os processos de trabalho e se pauta na tarefa colaborativa. Os autores evidenciam nesse estudo que a integralidade é uma premissa organizativa do trabalho, de natureza coletiva e multidisciplinar, valorando assim a importância do diálogo entre os sujeitos envolvidos no cuidado da comunidade, pois esses são os detentores dos diagnósticos das demandas do território e, por isso, a EPS, encontra a sua fundamentação nesta interdisciplinaridade, tendo como objeto de atuação o foco comunitário. Ainda, Ferreira et. al (2019), argumenta nesse contexto que para a consolidação da prática educacional é fundamental que haja elo entre gestão e profissionais da saúde, uma vez que esse processo de formação exige que seja de maneira reflexiva, participativa e contínua, voltada para as necessidades locais, dos serviços e das pessoas.

Nesse contexto, a RMSF, através da Educação Permanente em Saúde, fomentou na equipe o reconhecimento desses espaços de discussão, principalmente, por ser direcionado a abordagem multiprofissional e interdisciplinar. Ressalta-se que os debates entre as diversas categorias profissionais forneceram subsídios operacionais que auxiliaram em intervenções necessárias no dia a dia dessa equipe. Identifica-se, com isso, que a relevância social da comunidade só poderá ser levantada por meio das necessidades elencadas pelos trabalhadores inseridos no local e, por conseguinte com o olhar da própria população assistida. A partir de então poderá ser construído um ambiente de formação, em que há uma qualificação multiprofissional e, consequentemente, um aperfeiçoamento no atendimento ao usuário do SUS.

Reportando-nos a literatura sobre o papel da RMSF para a consolidação da EPS, podemos destacar o estudo realizado em Florianópolis - SC, onde essa especialização é reconhecida como condutora para a prática pedagógica na atenção primária à saúde. Isso significa que os trabalhadores reconhecem os residentes como capacitados para a solidificação dos espaços de EPS no município, tendo em vista que são capazes de promover encontros político-pedagógicos capazes de ressignificar os processos de trabalho em saúde, melhorar as condutas profissionais e fazer com que eles se sintam valorizados, uma vez que a EPS emerge de desafios e necessidades dos mesmos (Neto \& Bandeira, 2019). Assim como, Silva (2018), também evidencia o valor da residência como importante aparelho de educação permanente, visando à formação dos trabalhadores de saúde e ao fortalecimento do trabalho coletivo em saúde. $\mathrm{O}$ autor frisa ainda, que a participação de residentes, tutores e preceptores na 
EPS possibilita aos trabalhadores dos serviços repensarem e remanejarem suas práticas profissionais, principalmente, com a articulação entre a teoria e a prática, de modo a qualificar as ações em saúde baseadas em subsídios teóricos.

Nessas exposições é possível reconhecer a RMSF, a partir desse estudo e também da literatura vigente, como importante metodologia de consolidação do SUS, tendo em sua base de formação a EPS como potente ferramenta de apoio. Além disso, é evidente que os residentes certificam a legitimidade do trabalho interdisciplinar e multiprofissional, uma vez que estimulam, através dos encontros pedagógicos, a dinâmica de interação entre os diferentes núcleos que compõem a equipe. Com essa constatação, a residência, torna-se um influente método de motivação dos trabalhadores para os encontros de EPS, uma vez que os mesmos são capazes de trazer para prática a reflexão crítica do fazer em saúde e, principalmente, a troca de saberes entre os diversos intervenientes inseridos nesse local. Logo, soma-se, por meio da EPS, o sentido de cada profissão, ou seja, cada envolvido neste processo traz um novo (re)significado no fazer do outro, possibilitando, com isso, a troca entre os diferentes núcleos profissionais.

Os argumentos anteriormente elencados se aproximam dos princípios norteadores da Política Nacional de Educação Permanente em Saúde (PNEPS), nos quais evidenciam que os trabalhadores da saúde devem seguir a premissa de que as atividades de EPS servem como um espaço de troca de conhecimento entre os diversos saberes de cada núcleo profissional e como um meio de atualização baseado na realidade de cada população. Essa Política ressalta que as ações de saúde devem ter como ponto de partida a problematização das necessidades da população, pois só assim será possível efetivar o processo de ensino e aprendizado no trabalho (Brasil, 2004).

Formar trabalhadores através da integração entre o ensino, o serviço e a comunidade é uma proposta do Ministério da Saúde (MS), por meio da implementação da PNEPS. O órgão federal tem por objetivo embasar as equipes de saúde, através de processos educativos, visando estimular a reflexão crítica no serviço. A proposta de intervenção é o encontro entre o mundo da formação e o mundo do trabalho através da interseção entre o aprender e o ensinar na realidade dos serviços.

O planejamento das práticas de EPS deve estar embasado nas necessidades do cotidiano de trabalho dos profissionais, ou seja, que os problemas identificados sejam os motivadores dos temas a serem abordados em processos educativos. Aspectos estes em que se concorda com Sena et al. (2017) por também acreditarmos que os encontros de educação quando alicerçados no compartilhamento de ações e saberes, permanentemente, produzem e reafirmam conhecimento. Além disso, permitem à equipe desenvolver autonomia, diálogo, relações mais igualitárias e uma postura reflexiva e inovadora em relação às formas de intervenção no seguimento saúde, doença e cuidado.

Nesta mesma direção, ressalta-se, ainda, que o recurso de educação permanente em saúde deva ser organizado através de atitudes e comportamentos dialógicos. Portanto, vale destacar que uma evidência importante encontrada com a realização desse estudo, foi que a rotina diária de atendimentos pela equipe, a indisponibilidade de tempo para planejar os encontros de EPS, o excesso de serviços burocráticos, a falta de data disponível no cronograma mensal da ESF e o desmembramento da equipe para capacitações fora da unidade de saúde colocam em risco a validade das atividades de educação.

Essa descoberta possibilitou visualizar a necessidade de articulações entre as esferas que regem o sistema, principalmente, referente à organização do trabalho, para que tais dificuldades não impeçam a legitimação do espaço de educação permanente em saúde. Fatos estes corroborados pelos resultados de uma revisão integrativa sobre a EPS na atenção básica em que $63 \%$ das publicações tratadas no estudo detectaram, sob a ótica dos profissionais da saúde, que as fragilidades para efetivação da prática educacional são: inadequações no cotidiano de trabalho, como sobrecarga de trabalho e quadro de pessoal aquém do necessário, a falta de planejamento para realização das iniciativas de EPS, a não valorização das iniciativas de EPS pela gestão e as características inadequadas das iniciativas de EPS desenvolvidas (Ferreira, Lorena et al 2019).

Ao encontro dessa publicação os autores Silva et al. (2016) e Maciel (2016), apontam a atuação da gestão como importante para as iniciativas de EPS, visto que são peças fundamentais para a constante organização e aperfeiçoamento das 
estruturas e, especialmente, dos processos. Diante disso, os atores responsáveis por coordenar a EPS no nível municipal, precisam ter clareza em seus objetivos no momento de utilizar a educação como uma estratégia de gestão, no sentido de construir uma nova forma de produção de conhecimento e de transformação das práticas de ensino-aprendizado no trabalho.

Por isso, torna-se relevante ter no cronograma mensal da ESF uma data definida para as reuniões de educação permanente em saúde, em que todos os profissionais da equipe estejam disponíveis na unidade de saúde, para que possam participar dos encontros. Acredita-se que definir o momento para EPS estimula o coletivo de trabalhadores a refletirem o seu fazer, se apropriarem dessa atividade de formação e, principalmente, darem a devida importância para a troca de saberes entre os profissionais nesse contexto. Para Pinheiro, Azambuja, \& Bonamigo (2018) o resultado disso se dá quando o trabalhador compreende o seu papel como educador, dessa forma, o mesmo passa a se basear na postura ética, reflexiva, humana e indissociável do processo de viver. Dessa maneira, é capaz de somar ao seu olhar clínico, a inserção de práticas educativas, modicando, positivamente o cotidiano do trabalho em saúde, logrando assim melhores resultados nas ações da APS.

Ao discutir os resultados encontrados com a realização deste estudo foi possível identificar a atuação da Residência Multiprofissional em Saúde da Família, como um importante dispositivo de consolidação das diretrizes e princípios do SUS. Essa assertiva proveio dos encontros das práticas de Educação Permanente em Saúde, onde percebeu-se uma motivação dos profissionais perante a valorização dos espaços coletivos, através, da reflexão, do diálogo e das novas possibilidades de agir em saúde. Este conjunto de fatores evidenciou haver um distanciamento do atendimento realizado no que cerne ao modelo assistencial, preferencialmente, em função de atividades rotineiras e de alta demanda de atendimento.

Com a constatação do acima descrito percebe-se a fragilidade quanto a promoção da saúde, logo, se tem um “cuidado" direcionado à doença já estabelecida. Conserva-se com isso, o modelo tecnicista, biologicista e hegemônico, muito presente ainda na sociedade contemporânea e que apesar de sua importância, ainda assim necessita de uma contextualização para o cuidado ampliado, isso significa também trabalhar com foco nas práticas de prevenção de agravos e promoção da saúde, através de políticas públicas, determinantes sociais das doenças e participação social.

Nessa situação, surge o seguinte questionamento: "Quem é o eixo transformador para a efetivação das práticas de educação permanente em saúde?" O trabalhador que está inserido no cotidiano do SUS e que muitas vezes não possui tempo, recursos humanos suficiente, nem material disponível para suprir as necessidades impostas nesta realidade? O usuário que procura a unidade de saúde, quando já possui um agravante patológico estabelecido e, que muitas vezes, não se sente responsável pelo seu autocuidado? Ou o gestor municipal que é o principal articulador no fornecimento de subsídios para qualificar o funcionamento das unidades de saúde?

Com este questionamento evidencia-se a importância da articulação do quadrilátero do SUS em que trabalhadores, usuários, formadores e gestores, reconhecidos como sendo atores sociais, planejam práticas que objetivam a transformação do modelo assistencial. Tal parceria avista desenvolver a educação de forma crítica e reflexiva com metas de melhorias na integralidade da atenção. O quadrilátero se embasa na necessidade de envolvimento participativo de todos os atores sociais, dando ênfase, principalmente, para a percepção dos trabalhadores, pois entende que são eles os principais envolvidos no processo da assistência e na realidade do cotidiano de trabalho e, com isso, conseguem pontuar as dificuldades que precisam ser valorizadas, como cabíveis de solução (Moreira et al., 2016).

Abre-se com isso mais uma oportunidade de discussão que se direciona para um processo de educação, pois quando se questiona responsabilidades, há a necessidade de reflexão sobre mudanças, individuais e/ou coletivas, para que as diferentes esferas aqui elencadas estabeleçam (Co)responsabilidades que serão capazes de gerar diálogos e possíveis mudanças no dia a dia de cada uma delas.

Considera-se oportunidade, sobretudo no momento em que se concorda com Domingos, Nunes, \& Carvalho (2015), ao citarem Campos (2013) quanto a importância da existência de espaços coletivos para a coprodução de sujeitos, pois nesse 
encontro ocorre a comunicação, a escuta, a expressão de desejos, os interesses, a discussão, a análise de aspectos da realidade e a possível elaboração de estratégias que venham ao encontro das soluções de necessidades.

Em vista disso, percebe-se, igualmente, o residente multiprofissional como um importante mediador/catalisador de estímulos. Mais que um agente de atividades operacionais e rotineiras, o mesmo agrega mudanças com vistas a formação e ao desenvolvimento pessoal, profissional e das equipes, pois ao valer-se da EPS como espaços democráticos, de reflexão crítica e de relações igualitárias oportuniza o planejamento de ações coletivas, trabalhando projetos que transcendem técnicas e capacitações pontuais, instigando a participação ativa de todos nesse processo, bem como a capacidade crítica e criadora dos sujeitos, com direcionamento à integralidade da atenção à saúde.

Para Silva et al. (2016) a residência multiprofissional é um dispositivo intercessor para a EPS, ou seja, que possibilita as práticas de educação, pois a formação dos profissionais residentes se dá por meio da necessidade do encontro entre os sujeitos, através do trabalho multiprofissional, característica principal das RMS e, por esse motivo, desencadeia novas possibilidades de agir em saúde. Para os autores as RMS se apropriam deste espaço intercessor, porque designa a formação de profissionais como atores de produção de saúde, que não possuem apenas a preocupação com o somatório das ações, mas, sobretudo, com o que existe entre elas, como o resultado de um processo singular, que proporciona mudanças.

Esses mesmos autores afirmam que a RMS, fundamentada por seus princípios norteadores, utilizam a EPS como eixo pedagógico estruturante para as ações em saúde. Vislumbram o processo de EPS como sendo uma importante ferramenta para possíveis mudanças nos modelos de gestão e atenção do SUS e, ainda, como um auxílio para atuar no cotidiano dos sujeitos (Silva et al., 2016).

Traçando um paralelo com os autores citados no parágrafo anterior, foi possível perceber, neste estudo, que a presença da Residência Multiprofissional em Saúde da Família, nesta unidade de saúde, serviu como um estímulo aos trabalhadores, de forma a repensar a realidade por eles vivida, tendo em vista as múltiplas e complexas necessidades da população. Acredita-se que realizar educação permanente em saúde serviu como resgate de um processo de trabalho efetivo, reflexivo e resolutivo, no qual já havia sido extinto, em decorrência, principalmente, de atividades rotineiras, tais como, alta demanda e burocratização do trabalho. Logo, a RMSF ao valer-se da EPS como fundamento pedagógico, também consegue instituir, de forma positiva, este método no fazer dos profissionais da saúde, reorganizando o processo de trabalho, por meio da atualização de temas emergentes nos locais de atuação dos profissionais, da reflexão e da discussão de casos entre a equipe multiprofissional e, especialmente, da apropriação dos espaços de EPS. Tendo como foco fomentador os determinantes e condicionantes do processo saúde-doença vivenciados pelos indivíduos, famílias e grupos sociais.

A Gestão do coletivo, ou seja, a participação direta dos trabalhadores nas intervenções necessárias nos seus próprios locais de atuação, democratizam os espaços de trabalho, desenvolvem a capacidade de aprender e de ensinar de todos os atores envolvidos e permitem a eles tecer estratégias diferenciadas e criativas, em prol da melhoria da qualidade da atenção à saúde e a humanização do atendimento. Com isso, é possível evidenciar que o debate e a problematização que ocorrem nos encontros de EPS possuem significado na formação profissional para a saúde, principalmente, como meio transformador das práticas do SUS. Nessa mesma orientação, Macêdo, Albuquerque, \& Medeiros (2014), argumentam que a formação para a saúde deve ser capaz de abordar a qualificação técnico-científica, que está no domínio da habilidade intelectual e, ainda, o desenvolvimento multiprofissional, que está no domínio da relação interpessoal. Segundo os autores a união de tais domínios permitirá aos trabalhadores problematizarem seu trabalho e, com isso, desenvolverem autonomia e protagonismo nos processos de produção de saúde.

A fragmentação da oferta de cursos por categorias ou temáticas pode constituir e fortalecer espaços de hegemonia disciplinar, interferindo nas relações microssociais, entre as profissões, na produção do trabalho e atenção à saúde. Assim, essa maneira de organizar a EP é contraditória aos pressupostos da multiprofissionalidade e interdisciplinaridade. Nesse sentido, ao 
se pensar no cotidiano e nas necessidades de um campo interdisciplinar, os discursos sinalizam avaliações negativas ao modo compartimentalizado, indicando a valorização sobre o aprendizado a partir dos coletivos, em processos contínuos

Outro aspecto a ser discutido é a necessidade de se repensar quanto ao planejamento das atividades de EPS. Segundo os participantes deste estudo, a dinâmica dos encontros, também é uma questão importante a ser valorizada, pois enfatizam que a exaustiva rotina de trabalho vivenciada por eles causa desmotivação e, quando as práticas de EPS não possuem métodos pedagógicos atrativos que envolvam os profissionais, os mesmos se sentem desinteressados e, consequentemente, se distanciam das atividades propostas. Além disso, convém salientar também a necessidade da rotatividade entre os profissionais responsáveis por mediar os encontros de educação permanente. As experiências apresentadas neste trabalho caracterizam a ação sincronizada entre os membros da equipe, como sendo uma boa prática de troca de saberes. Pressupõe-se com isso que a alternância nas funções, educador e educando, e aqui incluímos o próprio usuário no processo, trará plenitude nos resultados gerados pelo processo de educação.

Não obstante aos desafios e dificuldades discutidos, anteriormente, cabem também citar que muitas são as contribuições advindas da inserção das práticas de educação no cotidiano dos trabalhadores. Segundo as experiências relatadas pelos participantes, a EPS serve como atualização de conhecimento que permite o resgate de práticas de educação em saúde que já haviam sido esquecidas e, que se tornam necessárias para a resolução de problemas enfrentados no dia a dia. Além disso, sinalizam o desenvolvimento de EPS, como uma forma de responder às necessidades do usuário do SUS, principalmente em relação a qualificação das ações prestadas e quanto as formas de abordagem da comunidade.

Segundo França et al. (2016) as principais contribuições advindas da utilização da EPS como método de qualificação do serviço estão a qualificação dos próprios trabalhadores, a identificação de possíveis falhas no atendimento e a conscientização das reais necessidades de saúde do usuário. França et al. (2016) e, também Santos, Cavalcante, \& Amaral (2019) descrevem que a EPS é importante para as transformações e resoluções dos problemas enfrentados no cotidiano dos serviços, pois promove a reflexão do trabalho, as mudanças nos modos de organização e funcionamento do serviço, estimula e contribui para o trabalho em equipe, aperfeiçoamento, atualização e mudanças na prática e para melhor integração entre a equipe e a comunidade.

\section{Conclusão}

É indiscutível que a prática de Educação Permanente em Saúde deve ser considerada como método prioritário para o desenvolvimento e formação dos trabalhadores para o SUS, pois além da oportunidade de sustentar um aporte teóricoconceitual e técnico-assistencial, favorece também a conquista da integralidade e o aumento da resolutividade nos processos de trabalho e no cuidado ao usuário. Principalmente, por assegurar à integração multiprofissional, o despertar ético-político dos sujeitos e, ainda, o controle social.

Diante da importância do tema para a progressão de um trabalhador reflexivo e político que fortaleça a concretização do SUS constitucional, assinalamos a necessidade de ponderar que o agente de mudança não deve ser somente o sujeito/trabalhador, pois fica evidente que a condução da EPS advém da articulação conjunta, entre os trabalhadores, os gestores e os usuários do SUS. Percebo com isso, que quando (Co) responsabilizamos o trabalhador, como único catalisador de transformações nesse processo desviamos o foco de funções que provêm do esforço de outros atores, que também são intervenientes no desenvolvimento da EPS.

Por essa razão consideramos que a prática rotineira e de qualidade das instituições de saúde depende da relação de troca entre os diferentes atores que regem o sistema. À vista disso, fica claro que o sujeito/trabalhador só conseguirá desenvolver a educação de qualidade, no seu ambiente de trabalho, quando o gestor oportunizar subsídios básicos que estimulem os profissionais a quererem consolidar os espaços de discussão, reflexão e tomada de decisão em equipe. 
Em razão disso, apontamos que os subsídios básicos são causadores de estímulos aos trabalhadores, ao se identificar um esgotamento desses sujeitos, quando os mesmos entendem que a Educação Permanente em Saúde trás sentido ao trabalho desenvolvido por eles. Porém, ainda existem obstáculos que dificultam a execução e/ou aprimoramento das atividades de EPS. Dentre os quais, são citados: a precariedade da infraestrutura da unidade de saúde, o número de trabalhadores insuficiente à população atendida, o excesso de trabalhos burocráticos e a falta de incentivo para a abertura de espaços de discussão entre os trabalhadores, na qual é citado o cronograma da ESF, quando não é disponibilizada data que referencie tal prática, na própria unidade de saúde.

O caráter generalista na escolha das temáticas a serem abordadas para as equipes de saúde também é um fator que debilita as articulações coletivas que fortalecem a construção das práticas de educação. Para tanto, é necessário elencar, através dos diagnósticos comunitários, as principais carências locorregionais para então desenvolverem ações educativas diferenciadas, focadas nos determinantes sociais de cada população. Com isso, há um reconhecimento de uma cultura de educação no trabalho, por considerar expressiva a intervenção sinalizada pelo sujeito que está imerso no universo do ambiente produtor de saúde e doença.

Desse modo, identificamos o dever de resgatar uma Educação Permanente em Saúde que tenha a intenção de trabalhar "a saúde como sendo um direito de todos", visando proporcionar qualidade de vida não somente aos usuários do SUS, mas também aos trabalhadores.

Assim, foi possível, perceber através da experiência, a necessidade de mudanças nestes aspectos, pois a EPS é fundamentada na relação dialógica entre os sujeitos, visando intervenções pensadas em coletividade, de forma interdisciplinar e multiprofissional. No entanto, ainda se trabalha, na maioria das vezes, com um modelo tradicional em que as decisões são tomadas de forma verticalizada, desconsiderando, seguidamente, a participação dos trabalhadores e dos usuários nas tomadas de decisão.

Por isso, foi possível perceber que a Educação Permanente em Saúde é uma ferramenta valiosa que a Residência Multiprofissional em Saúde da Família pode utilizar como porta de entrada para a equipe da ESF, pois o residente utiliza um espaço, em que a equipe, entende como sendo deficitário e, isso permite a ele se inserir gradativamente a ela.

Apesar da RMSF utilizar a EPS, como metodologia de trabalho, ainda assim, tal atribuição não é responsabilidade primordial dela. Contudo, foi possível identificar, através de alguns relatos, que o residente ministrar estas atividades incentiva a continuidade dos encontros de EPS. Além disso, ressaltam que a saída dele no segundo ano de formação, para atividades de vivências em outros pontos da rede de atenção à saúde, permite a eles a aquisição de novos conhecimentos, porém, pode ser uma ameaça para o seguimento das atividades de EPS.

Constata-se, com isso, que o profissional ainda não se sente apto para orientar essas práticas de educação, principalmente, segundo os participantes, pela falta de tempo disponível para o planejamento e execução deste plano. Percebese, com isso, a necessidade de tal fato ser mais bem estudado pelos gestores e, pelos próprios trabalhadores da ESF, por meio, principalmente, da abertura de espaços de discussões entre as diferentes esferas do sistema. Vislumbra-se, com isso, a consolidação da relação dialógica entre os intervenientes do processo de educação, que ao longo do tempo serão capazes de entender e valorizar o saber de cada um deles e, com isso, estabelecer novos métodos de aprendizado no trabalho.

Diante deste contexto, evidenciamos ainda, que a realização das práticas de EPS, ultrapassa a necessidade de falar sobre um tema específico, pois, além disso, orienta a aproximação entre os diferentes atores da rede e por esse fato, deve ser pensada e realizada de modo a valorizar o aprendizado, visando proporcionar novos métodos orientadores da prática de saúde e, ainda, instigar o interesse deles para novos encontros e novas perspectivas que irão diferenciar a qualidade dos ambientes laborais desses profissionais e do atendimento prestado à comunidade. 
Perante ao exposto, identificamos que durante o processo de articulação das atividades de Educação Permanente em Saúde pode-se perceber o quanto o envolvimento da residência com tais práticas incentivou a equipe a querer consolidar este espaço, principalmente, por reconhecerem as novas formar de agir em saúde. De forma a citarem que os encontros serviam para atualização, reflexão do fazer individual e/ou coletivo, qualificação de informações prestadas à população, principalmente, quanto aos determinantes de saúde e doença, além da valorização do trabalho multiprofissional, interdisciplinar e transdisciplinar.

Assim, pode-se elucidar que o residente ao utilizar esse método pedagógico, também se dilui nesse universo de transformação, ao averiguarmos, no final deste estudo, o quanto a EPS agregou novas formas de agir e de intervir no meu dia a dia como trabalhador do SUS. Além disso, passou-se a entender a necessidade da construção de encontros que tenham como ponto disparador a EPS, mas que também sejam construídos com base num trabalho homogêneo, democrático, agregador, cooperativo e que sustentem os princípios e diretrizes do SUS.

Como dificuldade no desenvolvimento deste estudo, cita-se a coleta de dados ter sido realizada através da técnica de grupo focal, pois ficou evidente que reunir todos os profissionais foi o principal obstáculo para a realização desta etapa, pois o cronograma mensal da ESF é um impasse para o encontro entre os profissionais. Portanto, cabe refletir que tal dificuldade pode ser transposta também para as ações de EPS futuras.

Diante disso, apesar da dificuldade levantada, ainda assim, foi possível entender que a Educação Permanente em Saúde pode ser tratada como um plano transformador das práticas de saúde, na qual valoriza o encontro entre os profissionais e que induz a compreensão e a reflexão dos processos de trabalho já estabelecidos e as possíveis mudanças necessárias para que adiante qualifiquem a integralidade da atenção, o acolhimento, a clínica ampliada e a humanização do cuidado.

Logo, espera-se que esse estudo sirva de estímulo para que no futuro gestores e trabalhadores do SUS, tragam para o cotidiano de suas práticas a Educação Permanente em Saúde, de maneira a incorporá-la como metodologia de trabalho e, principalmente, como rotina nos serviços de saúde. Além disso, espera-se que com o estudo, ora apresentado, outras pesquisas sejam motivadas para aprofundamento de estratégias de qualificação da assistência e dos processos de trabalhos no SUS, através da Educação Permanente em Saúde, na perspectiva dos sujeitos envolvidos no cotidiano dos serviços.

\section{Referências}

Bardin, L. (2011). Análise de conteúdo. Edições 70.

Brasil (2004). Portaria n ${ }^{\circ}$ 198, de 13 de fevereiro de 2004. Institui a Política Nacional de Educação Permanente em Saúde como estratégia do Sistema Único de Saúde para a formação e o desenvolvimento de trabalhadores para o setor e dá outras providências Brasília: Ministério da Saúde.

Brasil (2018). Política Nacional de Educação Permanente em Saúde: o que se tem produzido para o seu fortalecimento? Ministério da Saúde

Brasil, Ministério da Saúde (2021). Residência Multiprofissional em Saúde da Família. Secretaria de Atenção Primária à Saúde. https://aps.saude.gov.br/ape/nasf/residenciamultiprofissional/

Campos, G. W. S. (2013). Um método para análise e co-gestão de coletivos: a constituição do sujeito, a produção de valor de uso e a democracia em instituições: o método da roda. (4a ed.), Hucitec, p. 1-236.

Campos, K. F. C., Sena, R. R., \& Silva, K. L. (2017). Educação permanente nos serviços de saúde. Esc Anna Nery, 21 (4). 10.1590/2177-9465-EAN-20160317 .

Carvalho, W. M. E. S., \& Teodoro M. D. A. (2019). Educação para os profissionais de saúde: a experiência da Escola de Aperfeiçoamento do SUS no Distrito Federal, Brasil. Ciência \& Saúde Coletiva, 24(6), 2193-201. 10.1590/1413-81232018246.08452019.

Brasil (1988). Constituição da República Federativa do Brasil de 1988. https://www2.senado.leg.br/bdsf/bitstream/handle/id /518231/CF88_Livro_EC91_2016.pdf

Domingos, C. M, Nunes, E. F. P. A., \& Carvalho, B. G. (2015). Potencialidades da Residência Multiprofissional em Saúde da Família: o olhar do trabalhador de saúde. Interface: comunicação, saúde, educação, 19 (55): 1221-32. 10.1590/1807-57622014.0653.

Ferreira, L., Barbosa, J. S. A, Esposti, C. D. D., \& Cruz, M. M. (2019). Permanent Health Education in primary care: an integrative review of literature. Saúde Debate, 43(120):223-39. 10.1590/0103-1104201912017. 
França, T., Pierantoni, C., Belisario, S., Medeiros, K., Castro, J., Cardoso, I., \& Garcia, A. (2016). A capilaridade da Política Nacional de Educação Permanente em Saúde no Brasil. Investigação Qualitativa em Saúde. CIAIQ2016, 2. https://proceedings.ciaiq.org/index.php/ciaiq2016/article/view/738/725

Macêdo, N. B., Albuquerque, P. C., \& Medeiros, K. R. (2014). O Desafio da Implementação da Educação Permanente na Gestão da Educação. Saúde Trab. Educ. Saúde, 12 (2): 379-401. https://www.scielo.br/pdf/tes/v12n2/a10v12n2.pdf

Maciel, J. A. C. (2016). Educação permanente em saúde para os cirurgiões-dentistas da estratégia saúde da família: o caso de Sobral, Universidade Federal do Ceará; 114 p. http://www.repositorio.ufc.br/bitstream/riufc/21829/3/2016_dis_jacmaciel.pdf

Moreira, T. M. M., Avila, M. M. M., Jorge, M. S. B., \& Leitão, I. M. T. A. (2016). Manual de Saúde Pública. Sanar.

Neto, F. T. P. \& Bandeira, A. C. N (2019). Residência multiprofissional em saúde da família como condutora de educação permanente na atenção básica. SANARE, 18(2), 78-85. https://sanare.emnuvens.com.br/sanare/article/view/1377/702

Pereira, A. S., Shitsuka, D. M., Parreira, F. J., \& Shitsuka, R. (2018). Metodologia da pesquisa científica. Núcleo de Tecnologia Educacional - NT. Universidade Federal De Santa Maria https://rep ositorio.ufsm.br/bitstream/handle/1/15824/Lic_Computacao_Metodologia-PesquisaCientifica.pdf?sequence $=1$

Pinheiro, G. E W., Azambuja, M. S., \& Bonamigo A.W. (2018). Facilidades e dificuldades vivenciadas na Educação Permanente em Saúde, na Estratégia Saúde da Família. Saúde em debate, 42, 187-197..1590/0103-11042018S415.

Pope, C., \& Mays, N. (2009). Pesquisa qualitativa na atenção à saúde. Artmed.

Rodrigues, D. C., Pequeno, A. M. C., Pinto, A. G. A., Carneiro, C., Machado, M. F. A. S., \& Magalhães, A. G. (2020). Permanent education and matrix support in primary health care: family health routine. Revista Brasileira de Enfermagem, 73(6): doi: http://dx.doi.org/10.1590/0034-7167-2019-0076

Santos, E. A. M. S. M., Cavalcante, J. R. Do C., \& Amaral, M. S. (2019). Contribuições da educação permanente na atenção primária à saude: uma revisão integrativa: uma revisão integrativa. Itinerarius Reflectionis, 15(3), 01-16. https://doi.org/10.5216/rir.v15i3.57578

Sena, R. R., Grillo, M. J. C., Pereira, L. D., Belga, S. M. M. F., França, B. D., \& Freitas, C. P. F. (2017). Educação permanente nos serviços de saúde: atividades educativas desenvolvidas no estado de Minas Gerais, Brasil. Revista Gaúcha Enfermagem, 38 (2). http://dx.doi.org/10.1590/19831447.2017.02.64031

Silva, L. A. A., Pinno, C., Schmidt, S. M. S., Noal, H. C., Gomes, I. E. M., \& Signor, E. (2016). A educação permanente no processo de trabalho de enfermagem. Rev. enferm. Cent.-Oeste Min, 6(3), 2349-61. http://www.seer.ufsj.edu.br/index.php/recom/article/view/1027/1168

Silva, L. B. (2018). Residência multiprofissional em saúde no Brasil: alguns aspectos da trajetória histórica. Revista Katálysis, 21 (1), 200-209. http://dx.doi.org/10.1590/1982-02592018v21n1p200 